\title{
On the Remuneration to Electrical Utilities and Budgetary Allocation for Substation Maintenance Management
}

\author{
Pedro J. Zarco-Periñán *, José L. Martínez-Ramos (D) and Fco. Javier Zarco-Soto \\ Departamento de Ingeniería Eléctrica, Escuela Superior de Ingeniería, Universidad de Sevilla, \\ Camino de los Descubrimientos, s/n, 41092 Sevilla, Spain; camel@us.es (J.L.M.-R.); \\ fjzarco@outlook.com (F.J.Z.-S.) \\ * Correspondence: pzarco@us.es
}

Citation: Zarco-Periñán, P.J.; Martínez-Ramos, J.L.; Zarco-Soto, F.J. On the Remuneration to Electrical Utilities and Budgetary Allocation for Substation Maintenance Management. Sustainability 2021, 13, 10125. https:/ / doi.org/10.3390/su131810125

Academic Editors: Mojtaba Mahmoodian and Le Li

Received: 11 August 2021

Accepted: 3 September 2021

Published: 10 September 2021

Publisher's Note: MDPI stays neutral with regard to jurisdictional claims in published maps and institutional affiliations.

Copyright: (C) 2021 by the authors Licensee MDPI, Basel, Switzerland. This article is an open access article distributed under the terms and conditions of the Creative Commons Attribution (CC BY) license (https:/ / creativecommons.org/licenses/by/ $4.0 /)$.
Abstract: The liberalization of electricity markets has produced a great change in electrical utilities. One of these changes has affected the methodology for setting their remuneration. Depending on the country, these are different. Despite the wide range of remuneration methodologies for the electricity market of each country, they all feature one common element: the remuneration of operation and maintenance. One of the messages that this remuneration transmits is the need to extend the useful life of the facilities to allow sustainable development. This article focuses on the remuneration schemes of electrical utilities, the classification of substations for the definition of their maintenance programs, and the budget allocation for the execution of maintenance in these critical infrastructures. The particularity of these facilities, in which it is generally necessary to de-energize some of their parts for maintenance, has also been taken into account. To this end, a simple methodology currently used is presented based on the standardization of the bays of the substations and their classification into levels of importance. This classification into levels enables the facilities to be grouped according to similarities in their maintenance plans, although they differ from each other in terms of the periodicity of the application of maintenance procedures. This methodology guarantees a similar distribution of maintenance activities and financial needs over the years. In addition, the methodology allows one to know the importance of each substation (since the greater the equivalent weight, the greater the importance). Finally, the application of the proposed methodology in a real case is presented. It shows the simplicity, effectiveness, and lamination of the budgetary allocation of the proposed methodology, this being the main contribution of the formulation.

Keywords: remuneration; electrical utilities; maintenance policies; asset management; substation maintenance; budgetary allocation

\section{Introduction}

Increasingly, sustainability is acquiring a fundamental role in all sectors. In fact, it is revealed in the Sustainable Development Goals of the United Nations [1]. The importance of energy and cities is reflected in several of the goals. Thus, for example, Goal 7, 11 and 12 make direct reference to them, and Goal 13 through the reduction of emissions, one of whose ways of achieving this is through renewable energy sources. With this, the electricity sector becomes a fundamental element to achieve sustainable development goals.

In recent decades, the electrical sector has undergone a major transformation on a worldwide scale. To increase efficiency in each of the activities, therefore, most countries have shifted from regulated and vertically structured companies of a monopolistic nature to companies with competing independent segments. These segments are essentially those of generation and of commercialization, in which market mechanisms for purchase/sale are designed and in which the efficiency lies within the market itself. However, other parts of the old companies, such as the transmission and distribution of electricity, are still considered as regulated monopolies, which results in a separation between activities [2]. 
This change in the paradigm of traditional regulation began to be applied in Chile in 1981, followed by England and Wales (1990), Norway (1991), and Argentina (1992) [3]. For the remaining countries in which it was subsequently applied, there was already a brief experience [4]. A retrospective view of the evolution of regulatory systems and some negative points that have been detected can be found in $[5,6]$. Even today, there are still countries moving towards this liberalization [7].

Transmission and distribution activities have the characteristics of natural monopoly due to their increasing economies of scale, since the fixed costs of investment, operation, and maintenance predominate over the variable factors. Furthermore, it is totally inefficient for two companies to compete in the same territory by duplicating the electricity infrastructures, and hence distribution activity is regulated as a natural monopoly [8]. In this case, market competition is replaced by state intervention through regulatory agencies. Those agencies not only encourage companies to carry out an efficient operation, maintenance, and investment plan that establishes and monitors their regulated revenues, but also ensure that the efficiency improvements achieved revert to consumers. And in addition, they must avoid any type of collusion that could occur between the companies [9]. Their regulated revenues include investments in infrastructure, costs of operation and maintenance, and other administrative and commercial costs. All of these factors are reflected by the regulator through the tariff: with this tariff the consumer must perceive when consumption is more expensive or more economical [10]; the companies, in addition to receiving an income that ensures the recovery of the capital invested and reasonable costs for the service provided, should be encouraged to improve efficiency and cost reduction [11]. However, this efficiency and cost reduction should not detract from the quality perceived by the customer [12] and always bearing in mind that the facilities are considered critical by the authorities [13].

One of the fundamental aspects of sustainable development is the lengthening of the useful life of equipment and facilities in perfect working order and safeguarding the safety of people and facilities. Through the remuneration it must be transmitted to the utilities. Therefore, one of the activities that are always remunerated is that of the maintenance of the assets that make up the network, and hence asset management becomes vitally important in electrical utilities [14]. Maintenance strategies can be classified as corrective, preventive, condition-based, or reliability-centered (the latter two could be grouped into one classification under the title of predictive maintenance). Corrective maintenance is the type used years ago and now is that which is used only at low voltage. It is only used when the element has failed and is either repaired or replaced depending on its cost. Preventive maintenance is a routine maintenance that is performed at fixed intervals of time. It detects possible incipient defects and increases the life cycle of the equipment. However, it may occur that maintenance is performed unnecessarily with the consequent risk of introducing a defect during handling, although in photovoltaic solar plants it is used [15]. In condition-based maintenance, the condition of the element is considered based on the main parameters. In this way, maintenance is carried out only when deemed necessary. The disadvantage is the cost in the case where many parameters must be monitored. In addition to the condition of the equipment, reliability-centered maintenance considers its importance and the economic consequences of a failure.

From a technical point of view, the maintenance of the elements that make up the network has been studied, whereby the transformer [16] and the circuit breaker [17] constitute the most analyzed components. Furthermore, methods for the assessment of the reliability and risk of different assets have been studied and therefore the optimal maintenance policy can be determined [18]. However, in large power companies, the widespread practice involves the allocation of economic maintenance allowances to each of the areas in which companies are divided. These areas are assigned the facilities of the specific geographical areas of their responsibility and often have autonomy in the use of their budgets, provided that they comply with the maintenance policies established by the maintenance programs. 
The works that study budget allocation systems are based on a complex and exhaustive study of the maintenance of each facility in which the following considerations are made: total number of failures occurred and total average duration of repairing process on a certain component type [19]; critical outage causes, and costs of repairs, energy not supplied and human resources [20]; outage frequency, outage time per fault, outage cost, power lost in average, maintenance cost, and overhaul cost [21]; outage records, failure rates, costs of each maintenance activity, historical maintenance budgets, and customer cost per interruption [22]; system average interruption frequency index (SAIFI), number and type of customers for each individual section, and failure rates for all components [23]; number of customers interrupted due to failure of a certain component, outage records, and cost and reliability impact of each maintenance activity [24]; degree of network reliability and effectiveness of preventive maintenance budget in the improvement of network reliability [25]; and number of customers interrupted, duration of interruption, energy not served, and cost of the failure [26].

By knowing each of these costs, an exact annual budget of the maintenance activity can be allocated as a breakdown of each of the activities. In addition, each year, and depending on the maintenance that the area had to carry out, it would have to be assigned one budget or another and therefore it would not be approximately homogeneous from one year to the next, which would lead to a workload not proportional to the staff assigned. This would have associated a series of undesirable consequences such as the use of a high number of man-hours to carry out the maintenance monitoring and planning; and an oversized staff in certain years and in others a lack of personnel, which would require having to contract it externally for a short period of time to carry out maintenance. In return, there would be an extreme accuracy in the budget that would not be compensated by the additional costs that would occur and that always, as in all maintenance work, will have small deviations that will depend on the extraordinary work that must be carried out due to the maintenance performed.

To all of the above, it must be added that there is a necessary information that is not exactly known, as is the case of the failure rates of the elements [27]. An estimate is the most you can hope to have. This implies having to assume hypotheses in this regard. These hypotheses make it necessary to accept an uncertainty that, due to the very attempt of accuracy of the method, it was desired that they did not exist. Considering the specific case of substations, which are considered critical installations within electricity companies [28], theoretical studies should be carried out to find the best budget allocation for each piece of equipment. However, this is not entirely realistic. When maintenance is carried out on equipment, it is necessary to de-energize all of the elements close to it. Thus, if it is a substation, when a bay is de-energized, all of the equipment that comprises it is maintained. For this reason, the entire bay is unavailable and this is when all of the equipment that comprises it must be maintained. If this were not the case, it would have to be de-energized more times, with the added problem of the possible lack of supply to customers or the risk that is run while the bay is unavailable.

Therefore, although from a theoretical point of view, the methods proposed in the literature allow a perfect budgetary allocation to be obtained, from a real point of view they are difficult to assume due to the above. That is why the proposed methodology tries to avoid these problems when applying them to maintenance. In this way, a similar scheduled maintenance load every year will be had, the de-energization of the bays will be used to carry out the maintenance of all the equipment that is in them, and highly specialized personnel to carry out the planning with possible complex programs will not be necessary.

The aim of this paper is twofold: on the one hand, to present the remuneration in European countries, showing the influence that maintenance has on it, and as a particular example, the case of remuneration in Spain is shown; on the other hand, to show a formulae used for years in Spanish electricity companies for the classification of substations into levels by which to assign their maintenance programs and the allocation of the maintenance budget in a simple way, with an equitable and homogeneous distribution throughout all of 
the years so that the number of people needed to carry it out does not fluctuate. With it, the problems mentioned that arise with the other formulas are avoided. This formula can attract a lot of attention for its simplicity, and even surprise, but nevertheless it is extremely effective in allocating the budget for substation maintenance. The method presented has a simplicity of calculation, a transparency in the assignment and an obligation to a correct and homogeneous planning that has favored its application for years. In addition, it does not need experts to keep budget control of this maintenance and allows the maintenance load of each year to be laminated, making a homogeneous distribution of it. Also, an example of its application is shown. In this way, a better knowledge of the remuneration mechanisms and a new methodology for budgetary allocation taking into account the reality of field work are presented.

To show the importance that maintenance has for the regulator and the electric companies, Section 2 of this study will show the state of the remuneration of electricity companies in Europe and Spain. In addition, as for budgetary allocation of maintenance it is necessary to know the maintenance activities to be carried out in a substation, a maintenance program used in electricity companies and the methodology of budgetary allocation for the realization of the maintenance is presented in Section 3. Section 4 illustrates how to apply the methodology to a specific case. Lastly, Section 5 explains the conclusions drawn for this study.

\section{Remuneration of Transmission and Distribution Companies}

Traditionally, the remuneration of electricity companies was based on a scheme known as rate-of-return or cost of service, whereby the remuneration of each company was calculated annually by adding up the operating costs incurred, the depreciation of gross fixed assets, and a rate of return applied to the net fixed assets. In this manner, the company received a remuneration in which it recovered everything invested plus an increase of an amount in accordance with the type of risk incurred (cost-plus or rate-of-return). After a process of business restructuring, companies have been regulated by incentives, whereby price limitation or income limitation formulae for periods of four or five years have been applied in most European countries and other parts of the world [29]. Not only do these models encourage efficiency and cost reduction, but companies are also made aware of their income ex ante and can therefore more easily manage their assets [30]. However, one of the most critical aspects of regulation is the information asymmetry between the regulator and the companies since the estimation of efficient costs by the regulator is based on the information provided by the companies themselves. To reduce this information asymmetry, either reference networks are used (which indicate the efficient network model), or the audits carried out by the regulatory body on existing facilities and those placed annually in service.

\subsection{Remuneration in Europe}

The design of the electricity tariff is the tool that the regulator uses to send messages to all parties involved in the electricity market. It must therefore convey to the market that the system must be managed optimally in both the short and long term so that the distribution business remains sustainable and customers feel protected. Hence, the tariffs should be sufficient for companies to recover the investment made in the deployment of the network and the cost of the financial conditions of the investment with a reasonable capital return in accordance with the risk assumed; the objectives of the incentive mechanism should be achievable; network deployment must be carried out efficiently; operational costs should be kept as low as possible; and the system tariff should be minimal from a global point of view, including generation, transmission, distribution, and commercialization; end users should be encouraged to make efficient use of energy, for example, through consumption outside peak demand.

At the outset, the remuneration method used in most countries was the remuneration of investments made by adding an additional profit to these investments. In this way, 
companies were secure in the knowledge that all of their investments would be recovered. However, they had no incentive to improve their efficiency, and could even favor the methods whereby their assets are unnecessarily extended, or their base costs are reduced to obtain greater remuneration. To avoid this inefficiency, regulation has evolved into a system of rewards and penalties that encourage companies to be efficient. The most commonly used systems are as follows: rate-of-return or cost of service, where the companies recover their total costs incurred (investment and operating costs) plus a yield rate on the investment made; price cap, where the maximum prices that the company can invoice the customer for each of the services provided are fixed, and the companies are thereby encouraged to lower their costs to increase their profits; and revenue cap, where the maximum revenue that the company can have is established, and it is adjusted depending on productivity improvements. Electricity companies can therefore maximize their profits by minimizing their total costs.

On the other hand, the cost reduction message of the regulator can induce companies to drastically reduce both their investment and maintenance costs which would lead to a degradation of quality of service. To avoid this scenario, the regulator includes quality indices that, in the case of non-compliance, carry penalties for the companies involved.

A general analysis of regulatory regimes in the member states of the European Union is carried out in [31]. By reducing the remuneration policies to those of revenue/price cap or rate-of-return, Table 1 shows the regulatory systems that apply in transmission (T) and distribution (D). The combined remuneration system applies a methodology based on a combination of the two main systems. Thus (for transmission and distribution), in Great Britain revenue based on rate-of-return with incentive-based regulation is applied; in Italy is a combined model of price cap for OPEX (operating expenditure) and rate-of-return for CAPEX (capital expenditure); and Lithuania is 50\% price cap and 50\% revenue cap. Portugal has a combined model of price cap for OPEX, standard costs in new investments and rate-of-return for CAPEX in transmission, while in distribution has a combined model of price cap for OPEX and rate-of-return for CAPEX. Finally, in Poland the combined system is in distribution mixed revenue with elements of incentive-based regulation.

Table 1. Remuneration system applied in transmission and distribution.

\begin{tabular}{cccc}
\hline Rate-of-Return & Revenue/Price Cap & Combined & Other \\
\hline Austria (T, D) & Belgium (T, D) & Great Britain (T, D) & Denmark (T) \\
Estonia (T, D) & Czech Republic (T, D) & Italy (T, D) & Hungary (T, D) \\
Greece (D) & Denmark (D) & Lithuania (T, D) & Poland (D) \\
Latvia (T, D) & Finland (T, D) & Portugal (T, D) & \\
Poland (T) & France (T, D) & \\
Spain (T, D) & Germany (T, D) & \\
& Greece (T) & \\
& Iceland (T, D) & \\
& Ireland (T, D) & \\
& Luxembourg (T, D) & \\
& Netherlands (T, D) & \\
& Norway (T, D) & \\
& Slovenia (T, D) & \\
& Sweden (T, D) & \\
\hline
\end{tabular}

\subsection{Remuneration of Spanish Distribution Companies}

In Spain, the electricity sector law introduced a new structure into the electricity sector by establishing a wholesale market for electricity production and separating commercial activity from electricity distribution. From that moment onwards, Spain has enjoyed the liberalization of the electricity power sector at the same time as its neighboring countries. In 1998, the recognized asset base was updated, and an efficiency factor was introduced. In 2008, a new remuneration model for transmission and distribution was generated for assets introduced after 2008. Due to mismatches between the income and costs of the sector, 
in 2012 the established remuneration was subsequently modified. Finally, in 2013, the new regulatory framework for transmission and distribution activities was established [32], and in 2015 the types of facilities and reference unit values of investment, operation, and maintenance were defined.

This new model of remuneration is based on the physical units put into operation as a fundamental factor of remuneration and is increased annually by ex-ante investments approved by the regulator, whereby financial compensation of $6.5 \%$ is allocated for the first regulatory period. The remuneration associated with physical units is associated with amortization, financial compensation, and operating and maintenance costs. The new model also recognizes another set of costs associated with other regulated tasks. In addition, incentives are included to improve the quality of service, to reduce losses, and to detect fraud. The regulatory periods are of six-year duration, except for the first period, and the assets (such as bays, power transformers, overhead lines, and underground lines) are classified in terms of their insulation voltage level or, in the case of lines, depending on the section of the conductor.

Remuneration is a sum of three components: amortization of physical assets where assets are valued as the average sum of the actual investment and the standard value; remuneration for investment, obtained from the rate of financial compensation; and remuneration for operation and maintenance, obtained by applying the standard costs to the physical units, corrected by the corresponding efficiency factor.

Once the end of the useful lifespan of the asset is reached, no further remuneration is received for the investment. However, the operation and maintenance are increased by applying an extension factor to its lifespan as an incentive to keep the facilities operative and to minimize replacement investments, thereby recognizing the increase in maintenance costs in these facilities.

With respect to investment plans, the companies will request approval of their investment plans accompanied by a report from the regional authorities and by the valuation of the investment to be made according to the unitary standards. There is also a mechanism to monitor the implementation of such plans.

\section{Methodology for Budgetary Allocation for Substation Maintenance}

\subsection{Maintenance Program of Electrical Substations}

Knowing the activities to be carried out in a substation, the economic allocation for its maintenance can be assessed. To do this, it is necessary to know what maintenance is done; with what scope; to which parts of the substation; and with what periodicity.

The maintenance program in the substations is an asset management model for the improvement of its effectiveness. This program defines the activities to be carried out (maintenance procedures) and their periodicity. The programs most widely used by utilities include periodic inspections of facilities through the corresponding checklist and the predictive maintenance of the main items of equipment (essentially condition-based maintenance of the element). Periodic inspections involve a visual examination of the installation by means of which conclusions are drawn regarding its general condition. With the predictive maintenance of the main items of equipment, their fundamental parameters are analyzed and then compared with those obtained in previous revisions of such equipment and in other examples of similar characteristics. Depending on the results obtained, it is possible that certain action must be taken, and subsequent adaptation or repair activity must be performed and, depending on the severity, it might need to be tackled urgently. In this way, corrective maintenance is avoided as much as possible since it should be the last type of maintenance to be applied in a substation. This maintenance is the one that is applied when there is untimely failure and, in this case, there is interruption in supply and loss of quality perceived by the consumers.

In a substation, the items of equipment are grouped in bays. A bay is a part in a substation which starts from a busbar to a feeder or vice versa, and composed of a circuit breaker and its associated equipment such as isolators, current transformer, disconnectors, 
etc. The bay constitutes the unit of revision: it is important to bear in mind that it is necessary to request the de-energization of a complete bay on carrying out the revision of one of its major elements. For this reason, when one of these elements is revised, the rest of the elements within the same bay are also inspected.

Without going into detail, since it is not the purpose of this paper, the maintenance program in a substation is defined in terms of the scope and periodicity of the actions, which can be summarized as follows: periodic inspection, regulatory inspection, thermographic inspection, inspection by activity, inspection of protection relays, predictive maintenance, and maintenance of the bay. While in the first three cases it is not necessary to de-energize the facility, the opposite is true in the other cases.

During periodic inspection, a tour of the substation in service is carried out and the points defined in the corresponding maintenance procedures of the equipment are reviewed. In regulatory inspection, regulatory aspects of the facility are examined to verify the fulfillment of the regulations. Thermographic inspection requires the taking of temperature measurements of the facility when it is in service and energized to detect points whose heat exceeds normal levels.

In other cases, de-energizing the equipment to be worked on is necessary. That happens in inspection by activity, where the maintenance of certain equipment is performed when it exceeds a certain number of actions (this would mainly be the case for medium-voltage circuit breakers, on-load tap-changers, and compressors); or in inspection of protection relays, to carry out tests on the protection of the bay. The same happens in predictive maintenance to verify the state of an item of equipment by comparing data and parameters obtained periodically. And in maintenance bay, where when carrying out the maintenance of the main element of the bay (such as the circuit breaker or power transformer), the rest of the components of the bay (such as disconnectors, measurements transformers, and busbars) should also be revised.

Within predictive maintenance, the main equipment on which maintenance is carried out is that of the power transformers, the circuit breakers, and the direct current battery.

Regarding the periodicity of the actions, this depends on the importance of the substation, whereby the maintenance in facilities considered to be of greater importance is more frequent.

\subsection{Maintenance Costs per Bay}

A medium-sized electricity company can have more than 1000 substations, more than 100,000 transformation centers, and more than $300,000 \mathrm{~km}$ of lines, so its maintenance budget is quite high. In addition, it has a responsibility to provide good quality service to customers, quality that is measured annually by the regulatory body. This budget that the company spends annually on maintenance will be defined by its policy. From a technical point of view this will be that which is necessary to execute its ordinary maintenance plans or the extraordinary ones that it is wished to undertake. The amount received by the regulatory body, or a greater or lesser quantity, may be fully used depending on the annual investment plans of the company, the average age of its facilities, the quality indices of recent years, the penalties it may have received, etc. From an economic point of view, the budget will be defined by the results that the company wants to offer, the dividends to the shareholders and any other economic measure that marks its future. Therefore, the budget used for maintenance in an electricity company will be defined by a combination of technical-economic circumstances that will be defined by the company's management.

Independently of the budget that will be assigned to the maintenance of the substations from the senior management, it is necessary to calculate what is really necessary to undertake the maintenance plans. Once the maintenance plan of a substation has been established, defining the scope to be carried out on each component and its periodicity, the cost involved in carrying it out can be estimated. For this, it is necessary to consider the number of people involved in the maintenance, the time spent doing it and the materials used to carry it out. To avoid possible errors when calculating, which may be affected 
by the incorrect allocation of all the costs that affect, the most real thing is to obtain the assessment given by companies specialized in the maintenance of substations. From this information it can be concluded that there is proportionality in the maintenance costs between the different bays of a substation (it must be considered that the composition of a bay is usually homogeneous regardless of its tension, the only difference being the tension of the elements that they compose it and its possible complexity). Once the cost is known, depending on whether each maintenance is performed each one, three or six years (they are the most common in all electric companies), it is possible to annualize the cost and obtain the proportional part corresponding to each year.

The experience in the valuation of such works leads to the fact that there may be a variation between the costs of the work from one region to another due to the variable costs, mainly the labor costs. However, in each region that which remains constant is the proportionality between maintenance costs in each bay depending on its tension. For this reason, and in order not to give absolute cost values that may vary from one region to another depending on where the work is carried out, Table 2 shows that proportionality considering the cost of maintenance in a $400 \mathrm{kV}$ bay it is 1000 monetary units (where HV high voltage and MV medium voltage).

Table 2. Maintenance costs in substations.

\begin{tabular}{cc}
\hline Bay & Monetary Units \\
\hline $400 \mathrm{kV}$ & 1000 \\
$220 \mathrm{kV}$ & 800 \\
$132-110 \mathrm{kV}$ & 680 \\
$66-50 \mathrm{kV}$ & 420 \\
$45 \mathrm{kV}$ & 240 \\
Medium voltage bay & 100 \\
Power transformer & 550 \\
HV /HV & 550 \\
HV/MV & 170 \\
MV/MV &
\end{tabular}

\subsection{Budgetary Allocation for Maintenance}

In an electricity company, the maintenance department is in charge of introducing any new maintenance techniques that arise. These techniques are gradually being introduced into facilities considered as pilot schemes and from where their suitability and ease of implementation is verified before being extended to the rest of the company. The maintenance department is also responsible for issuing guidelines to be followed in the different geographical areas in which companies are usually divided. It is in these areas where management decisions are taken directly and where the maintenance program is planned and executed. At the same time, the maintenance department allocates the economic resources according to established criteria. These economic resources can be those that the electricity company has received from the regulatory body or those that the senior management of the electricity company considers appropriate from a technical and economic point of view, and it can vary from one year to another. It is in the homogeneous and equitable distribution of those general economic resources already assigned by the direction in which this paper focuses next, since the total allocation is defined once the general budgets of the company are set and it escapes from this scope.

In addition, the allocation methodology must be clear, simple, and objective to avoid possible discrepancies that may arise between the different areas to obtain the largest possible budget for their needs. Do not forget that in a company, although budget allocations may be given, the maintenance areas will always have enough importance and responsibility to be able to discuss and negotiate their budgets. Therefore, the clarity and simplicity of the presented methodology is necessary to avoid as much as possible any discussion and offer a unique criterion. In this way, if any area does not agree with the allocation that has corresponded to it and makes a proposal for a new methodology, it 
will be necessary to approve the new allocation system and change it for all areas for the following year. Likewise, it should be remembered that the maintenance areas manage the day-to-day running of the electrical installations. For this reason, it is very important that the effort dedicated to financial management be as little as possible, although of course, it must be done with all of the rigor required.

Maintenance activities are basically defined by the maintenance program of each company. The economic allocation to each area for these programs is calculated considering the facilities in each geographical area, since such maintenance is homogenous for the whole company. Therefore, depending on the number and size of the facilities, a budget can be allocated to meet: the needs of preventive and predictive maintenance (which can be calculated in accordance with maintenance plans); and also of corrective maintenance that can normally arise as a consequence of the maintenance carried out through maintenance programs or untimely failures included within the fault rates of the equipment itself (which is an estimate of the average expense used in similar installations in corrective maintenance). Each activity is associated with a budget depending not only on its scope but also on the frequency with which it must be executed, which depends on the importance of the facilities in that area. To carry out this economic allocation, a weight is given to each installation and in this way the economic resources can be distributed in a homogeneous and equitable way. This weight depends on the size and importance of each substation.

Equivalent bay or equivalent weight is defined as the percentage at which any bay or transformer of a substation is equivalent to the $400 \mathrm{kV}$ bay which is considered as the unit. In this way, it is possible to standardize the workload supposed by each bay or transformer and make it comparable from an economic point of view. Hence, the equivalence is given in Table 3 and that is based on the maintenance costs of Table 2. This proportionality has already been found and applied for other purposes. Thus, a similar methodology was carried out for the transfer of transmission assets between companies in Spain.

Table 3. Equivalent weights in substations.

\begin{tabular}{cc}
\hline Bay & Equivalent Weight \\
\hline $400 \mathrm{kV}$ & 1 \\
$220 \mathrm{kV}$ & 0.8 \\
$132-110 \mathrm{kV}$ & 0.68 \\
$66-50 \mathrm{kV}$ & 0.42 \\
$45 \mathrm{kV}$ & 0.24 \\
Medium voltage bay & 0.1 \\
Power transformer & \\
HV/HV & 0.55 \\
HV/MV & 0.55 \\
MV/MV & 0.17 \\
\hline
\end{tabular}

In this way, a substation can be assigned a weight as a result of the sum of the weights of the equivalent bays and transformers that it contains. This weight enables the substations to be grouped according to their size. This grouping of substations can also be performed in terms of their power. In the case where the assignment level is a consequence of the installed power and not of the weight of the installation itself, it is assigned the minimum weight of that level. The levels at which substations can be grouped are expressed in Table 4. In addition, substations may change their level due to the environmental conditions they suffer, their level of technology, or the criticality or sensitivity of the market that they supply. 
Table 4. Substation levels.

\begin{tabular}{ccc}
\hline Level & Equivalent Weight & Transformation Power (MVA) \\
\hline A & $\geq 3$ & $\geq 150$ \\
B & $3>$ Weight $\geq 1$ & $150>$ Power $\geq 10$ \\
C & $<1$ & $<10$ \\
\hline
\end{tabular}

Therefore, all substations have an assigned equivalent weight and, as a sum of all the installations of an area, the area is assigned a weight. Consequently, based on a budget, it can be distributed across all areas in a homogeneous and equivalent way to deal with all their maintenance, except that which is a consequence of force majeure, for which an extraordinary budget must be provided.

Figure 1 shows a flowchart of the proposed method. Thus, knowing the bays and the power transformers, the equivalent weight of each substation can be calculated using Table 3 . Furthermore, with this information the level of the substation is known through Table 4. Adding all the equivalent weights of the substations that make up an area, the equivalent weight of the area can be found. In this way, by adding the equivalent weights of all of the areas, it is possible to know the percentage of what each one influences the utility. This percentage will be the one used for the budgetary allocation of substation maintenance.

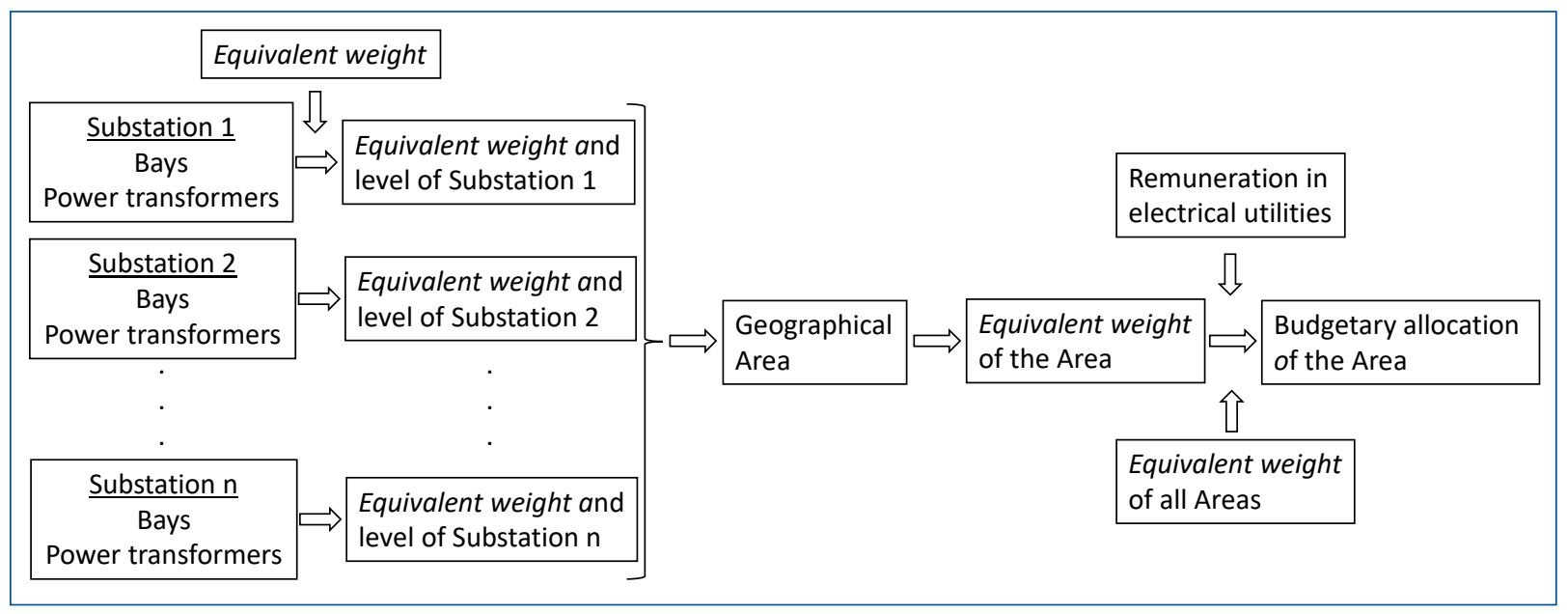

Figure 1. Methodology flowchart.

\section{Case Study}

In the proposed method, the most important factor is its simplicity. All that is needed for its implementation is a basic database updated with the facilities of each area, which must indicate the number of bays grouped by voltage and the number of transformers with an indication of their power and their voltages in high and medium voltage. With this information, the equivalent weight of the substation and the area on which it depends can be obtained.

To establish the budget that is used for the maintenance of the substations, information regarding the needs of each area is requested, with details on the periodic maintenance reflected in the maintenance programs and the special campaigns to be carried out. Once this information is ascertained and the total budget allocated to the periodic maintenance is fixed by planning and management control department, then the allocation that corresponds to each area is completed. This budget includes both the maintenance programs and the corrective maintenance that can be derived from the revisions made. It is in this assignment that the method presented is applied.

For an illustration of how the proposed method can be applied, the allocation of the budget available for maintenance to a part of the network of a Spanish company is carried 
out. The facilities are described in Table 5, i.e., a network with four different voltages $(220 \mathrm{kV}, 132 \mathrm{kV}, 66 \mathrm{kV}$ and MV) that is divided into four areas (North, East, South and West) each of which is responsible for managing the substations in its geographical area.

Table 5. Number of bays and transformers by area and substation.

\begin{tabular}{|c|c|c|c|c|c|c|c|c|c|}
\hline Substation & $220 \mathrm{kV}$ & $132 \mathrm{kV}$ & $66 \mathrm{kV}$ & MV & $\begin{array}{c}220 / 132 \\
(150 \text { MVA) }\end{array}$ & $\begin{array}{c}220 / 66 \\
\text { (120 MVA) }\end{array}$ & $\begin{array}{c}132 / 66 \\
\text { (70 MVA) }\end{array}$ & $\begin{array}{c}\text { 132/MV } \\
\text { (30 MVA) }\end{array}$ & $\begin{array}{c}\text { 66/MV } \\
\text { (30 MVA) }\end{array}$ \\
\hline \multicolumn{10}{|l|}{ North } \\
\hline \multicolumn{10}{|l|}{ Area } \\
\hline N-1 & 5 & 6 & & & 2 & & & & \\
\hline $\mathrm{N}-2$ & & 3 & & 8 & & & & 1 & \\
\hline N-3 & & 3 & & 10 & & & & 1 & \\
\hline N-4 & & 3 & & 8 & & & & 1 & \\
\hline \multicolumn{10}{|l|}{ East Area } \\
\hline E-1 & 5 & & 7 & 10 & & 2 & & & 1 \\
\hline $\mathrm{E}-2$ & & & 7 & 20 & & & & & 2 \\
\hline E-3 & & & 6 & 20 & & & & & 2 \\
\hline \multicolumn{10}{|l|}{ South } \\
\hline \multicolumn{10}{|l|}{ Area } \\
\hline S-1 & & 5 & 9 & 10 & & & 2 & & 1 \\
\hline S-2 & & & 1 & 8 & & & & & 1 \\
\hline S-3 & & & 7 & 10 & & & & & 1 \\
\hline S-4 & & & 1 & 8 & & & & & 1 \\
\hline \multicolumn{10}{|l|}{ West Area } \\
\hline O-1 & & & 8 & 16 & & & & & 2 \\
\hline $\mathrm{O}-2$ & & & 3 & 8 & & & & & 1 \\
\hline O-3 & & & 5 & 10 & & & & & 1 \\
\hline O-4 & & & 3 & 10 & & & & & 1 \\
\hline
\end{tabular}

Table 6 shows the level to which each substation corresponds, which in turn defines their individual maintenance programs. The level of each substation is obtained from the number of bays and transformers that each of them has (Table 5), affecting them by their equivalent weight (Table 3). Thus, the equivalent weight of the substation is obtained by multiplying each bay and transformer by its corresponding equivalent weight and adding all those found in the substation. Once known, the substation level is determined according to Table 4. Equivalent weight of each Area is obtained as the sum of the equivalent weights of all the substations found in that Area. Thus, the equivalent weight of the entire utility is obtained as the sum of the corresponding equivalent weights of the substations of all the Areas. In this simple way, the percentage that each Area has in the total of the utility is calculated. That same percentage is applied as a budgetary allocation for maintenance tasks. In addition, the methodology allows to know the importance of each substation and Area since the greater the equivalent weight, the greater the importance.

Both in the south area and in the west area there are substations with level B, which implies that their maintenance programs have a periodicity that differs from those of level A. In that with level B, their revisions are more widely time-spaced, although the scope of the actions remains similar. Level $C$ substations (which in this example have not appeared) usually correspond to installations that feed low-load or MV/MV substations.

As has been shown, the proposed method allows, on the one hand, to classify the substation in a level to assign it a maintenance program, and on the other, the budgetary allocation to carry it out. Both results are obtained in a simple way and thus a homogeneous distribution of both maintenance activities and financial needs is guaranteed every year. 
Table 6. Substation level, equivalent weight of the area, and percentage of budget allocation.

\begin{tabular}{|c|c|c|c|c|}
\hline Substation & $\begin{array}{c}\text { Equivalent Weight of } \\
\text { the Substation }\end{array}$ & Substation Level & $\begin{array}{c}\text { Equivalent Weight of } \\
\text { the Area }\end{array}$ & $\begin{array}{c}\text { Budgetary Allocation } \\
\text { of the Area (\%) }\end{array}$ \\
\hline North Area & & & 19.75 & 26.7 \\
\hline $\mathrm{N}-1$ & 9.18 & A & & \\
\hline $\mathrm{N}-2$ & 3.39 & A & & \\
\hline $\mathrm{N}-3$ & 3.59 & $\mathrm{~A}$ & & \\
\hline $\mathrm{N}-4$ & 3.39 & $\mathrm{~A}$ & & \\
\hline East Area & & & 21.25 & 28.7 \\
\hline E-1 & 9.59 & A & & \\
\hline $\mathrm{E}-2$ & 6.04 & $\mathrm{~A}$ & & \\
\hline E-3 & 5.62 & $\mathrm{~A}$ & & \\
\hline \multicolumn{5}{|l|}{ South Area } \\
\hline S-1 & 9.83 & $\mathrm{~A}$ & 17.86 & 24.1 \\
\hline S-2 & 1.77 & B & & \\
\hline S-3 & 4.49 & $\mathrm{~A}$ & & \\
\hline S-4 & 1.77 & $\mathrm{~B}$ & & \\
\hline \multicolumn{5}{|l|}{ West Area } \\
\hline O-1 & 6.06 & $\mathrm{~A}$ & 15.13 & 20.5 \\
\hline $\mathrm{O}-2$ & 2.61 & $\mathrm{~B}$ & & \\
\hline $\mathrm{O}-3$ & 3.65 & $\mathrm{~A}$ & & \\
\hline $\mathrm{O}-4$ & 2.81 & B & & \\
\hline
\end{tabular}

\section{Conclusions}

Electricity companies worldwide have evolved from integrated utilities with generation, transmission, distribution, and commercialization into separate competitive companies within which some of their activities, such as transmission and distribution, are considered natural monopolies. This paper has reviewed the remuneration systems of such companies in European countries in general, and of that in Spain in particular. Across all remuneration systems, the common denominator is the remuneration of operation and maintenance. Even in Spain, as occurs in other countries, once the average lifespan of the facility has been exceeded, this remuneration is increased, not only in recognition of the increase of these costs but also to encourage their continued operation. That is, remuneration policies promote the maintenance of the facilities and hence the extension of their useful lifespan.

The responsibility for the management of electricity companies is divided into smaller areas each of which is responsible for managing the facilities in its geographical area. However, the maintenance carried out therein is similar and is established by various maintenance programs that each company defines. In this way, the good behavior of the facility and the quality of service provided to its customers is guaranteed. The scope of the actions to be carried out in the main elements that make up the substation has been dealt with in numerous papers. Nonetheless, the economic distribution to the different areas to undertake such maintenance actions has been largely overlooked. Furthermore, the methods proposed in the literature are complex and require information that most of the time is not available.

This paper presents a methodology for such economic apportioning with a homogeneous rule and in accordance with the volume of substations in each area. This methodology is based on the definition of equivalent bay and equivalent weight, already used for the transfer of transmission assets between companies in Spain. The key to this methodology is not only its simplicity, clarity, and prevention of exposure to conflicting interpretations, but also the fact that it lends greater importance to facilities considered critical or problematic. And these characteristics are what make it so attractive to be used, and even surprising.

The simplicity of operation of this methodology has been illustrated with the allocation of the budget available for maintenance in a company divided into several geographical areas. With the simple calculation of a few multiplications and additions the classification of the substation to assign its maintenance program and the budgetary allocation has been 
made. In addition, the importance of each substation and area has also been identified, since the greater the equivalent weight, the greater the importance

In conclusion, considering society's awareness that resources are limited, any regulation aimed at preserving them is well accepted by all parties involved, as in the case of maintenance remuneration. To achieve it, one must take into account the factors that affect it and that are accepted by each of the parts involved; it would be advisable that it be a simple and easy to apply methodology.

Author Contributions: Conceptualization, P.J.Z.-P. and J.L.M.-R.; methodology, P.J.Z.-P. and F.J.Z.-S.; validation, P.J.Z.-P., F.J.Z.-S. and J.L.M.-R.; formal analysis, P.J.Z.-P., F.J.Z.-S. and J.L.M.-R.; investigation, P.J.Z.-P. and F.J.Z.-S.; data curation, F.J.Z.-S.; writing-original draft preparation, P.J.Z.-P.; writing-review and editing, P.J.Z.-P., F.J.Z.-S. and J.L.M.-R.; visualization, P.J.Z.-P. and F.J.Z.-S.; supervision, P.J.Z.-P.; project administration, P.J.Z.-P.; funding acquisition, P.J.Z.-P. All authors have read and agreed to the published version of the manuscript.

Funding: This research received no external funding.

Institutional Review Board Statement: Not applicable.

Informed Consent statement: Not applicable.

Data Availability Statement: Not applicable.

Acknowledgments: The authors would like to thank eCitySevilla project for providing facilities to conduct the research. The authors would like to acknowledge the support of the Spanish State Research Agency under Grant No. PID2020-116433RB-I00 (PID2020-116433RB-I00/AEI/10.13039/501100011033).

Conflicts of Interest: The authors declare no conflict of interest.

\section{References}

1. United Nations Educational, Scientific and Cultural Organization (UNESCO). Available online: https://en.unesco.org/sdgs (accessed on 29 June 2020).

2. Rothwell, G.; Gómez, T. Electricity Economics: Regulation and Deregulation; IEEE-Wiley Press: Piscataway, NJ, USA, 2003.

3. Battele, C.; Barroso, L.A.; Pérez-Arriaga, I.J. The changing role of the State in the expansion of electricity supply in Latin America. Energy Policy 2010, 38, 7152-7160. [CrossRef]

4. Jamasb, T.; Pollitt, M. Incentive regulation of electricity distribution networks: Lessons of experience from Britain. Energy Policy 2007, 35, 6163-6187. [CrossRef]

5. Alexander, I. Developing countries experience and outlook: Getting the framework right. Util. Policy 2014, 31, 184-187. [CrossRef]

6. Gassner, K.; Pushak, N. 30 years of British utility regulation: Developing country experience and outlook. Util. Policy 2014, 31, 44-51. [CrossRef]

7. Yin, J.; Yan, Q.; Lei, K.; Balezentis, T.; Streimikiene, D. Economic and efficiency analysis of China electricity market reform using computable general equilibrium model. Sustainability 2019, 11,350. [CrossRef]

8. Viscusi, W.K.; Vernon, J.M.; Harrington, J.E. Economics of Regulation and Antitrust, 2nd ed.; MIT Press: Cambridge, MA, USA, 1995.

9. Aliabadi, D.E.; Kaya, M.; Sahin, G. Determining collusion opportunities in deregulated electricity markets. Electr. Power Syst. Res. 2016, 141, 432-441. [CrossRef]

10. Oprea, S.V.; Bara, A.; Tudorica, B.G.; Dobrita, G. Sustainable development with smart meter data analytics using NoSQL and self-organizing maps. Sustainability 2020, 12, 3442. [CrossRef]

11. Reneses, J.; Rodríguez, P. Distribution pricing: Theoretical principles and practical approaches. IET Gener. Transm. 2014, 8, 1645-1655. [CrossRef]

12. Drosos, D.; Kyriakopoulos, G.L.; Arabatzis, G.; Tsotsolas, N. Evaluating customer satisfaction in energy markets using a multicriteria method: The case of electricity market in Greece. Sustainability 2020, 12, 3862. [CrossRef]

13. Greiving, S.; Fleischhauer, M.; León, C.D.; Schödl, L.; Wachinger, G.; Miralles, I.K.Q.; Larraín, B.P. Participatory assessment of multi risks in urban regions-The case of critical infrastructures in Metropolitan Lima. Sustainability 2021, 13, 2813. [CrossRef]

14. Khuntia, S.R.; Rueda, J.L.; Bouwman, S.; Van Der Meijden, M.A.M.M. Classification, domains and risk assessment in asset management: A literature study. In Proceedings of the 50th International Universities Power Engineering Conference (UPEC), Stoke-on-Trent, UK, 1-4 September 2015; pp. 1-5. [CrossRef]

15. Baklouti, A.; Mifdal, L.; Dellagi, S.; Chelbi, A. An optimal preventive maintenance policy for a solar photovoltaic system. Sustainability 2021, 12, 4266. [CrossRef]

16. $\mathrm{Wu}, \mathrm{Q}$;; Zhang, $\mathrm{H}$. A novel expertise-guided machine learning model for internal fault state diagnosis of power transformers. Sustainability 2019, 11, 1562. [CrossRef] 
17. Dehghanian, P.; Guan, Y.; Kezunovic, M. Real-time life-cycle assessment of high-voltage circuit breakers for maintenance using online condition monitoring data. IEEE Trans. Ind. Appl. 2018, 55, 1135-1146. [CrossRef]

18. Piasson, D.; Bíscaro, A.A.P.; Leao, F.B.; Mantovani, J.R.S. A new approach for reliability-centered maintenance programs in electric power distribution systems based on multiobjective genetic algorithm. Electr. Power Syst. Res. 2016, 137, 41-50. [CrossRef]

19. Dehghanian, P.; Moeini-Aghtaie, M.; Fotuhi-Firuzabad, M.; Billinton, R. A practical application of the Delphi method in maintenance-targeted resource allocation of distribution utilities. In Proceedings of the International Conference on Probabilistic Methods Applied to Power Systems (PMAPS), Durham, UK, 7-10 July 2014; pp. 1-6. [CrossRef]

20. Firouz, M.H.; Ghadimi, N. Optimal preventive maintenance policy for electric power distribution systems based on the fuzzy AHP methods. Complexity 2015, 21, 70-88. [CrossRef]

21. Lehtonen, M. On the optimal strategies of condition monitoring and maintenance allocation in distribution systems. In Proceedings of the 9th International Conference on Probabilistic Methods Applied to Power Systems (PMAPS), Stockholm, Sweden, 11-15 June 2006; pp. 1-5. [CrossRef]

22. Phoothong, N.; Vanittanakom, P.; Teera-achariyakul, N.; Rerkpreedapong, D. Optimal preventive maintenance budget setting for electric power distribution utilities. In Proceedings of the 5th International Conference on Electrical Engineering/Electronics, Computer, Telecommunications and Information Technology (ECTI-CON), Krabi, Thailand, 14-17 May 2008; pp. 957-960. [CrossRef]

23. Sittithumwat, A.; Soudi, F.; Tomsovic, K. Optimal allocation of distribution maintenance resources with limited information. Electr. Power Syst. Res. 2004, 68, 208-220. [CrossRef]

24. Teera-achariyakul, N.; Chulakhum, K.; Rerkpreedapong, D.; Raphisak, P. Optimal allocation of maintenance budgets for reliability target setting. In Proceedings of the Asia-Pacific Power and Energy Engineering Conference (APPEEC), Chengdu, China, 28-31 March 2010; pp. 1-4. [CrossRef]

25. Tehrani, M.K.; Fereidunian, A.; Lesani, H. Financial planning for the preventive maintenance of power distribution systems via fuzzy AHP. Complexity 2014, 21, 36-46. [CrossRef]

26. Yeddanapudi, S.R.K.; Li, Y.; McCalley, J.D.; Chowdhury, A.A.; Jewell, W.T. Risk-based allocation of distribution system maintenance resources. IEEE Trans. Power Syst. 2008, 23, 287-295. [CrossRef]

27. Yahaya, M.S.; Azis, N.; Selva, A.M.; Kadir, A.Z.A.A.; Jasni, J.; Hairi, M.H.; Ghazali, Y.Z.Y.; Talib, M.A. Effect of pre-determined maintenance repair rates on the health index state distribution and performance condition curve based on the Markov prediction model for sustainable transformers asset management strategies. Sustainability 2018, 10, 3399. [CrossRef]

28. Fan, Y.; Li, J.; Zhang, D.; Pi, J.; Song, J.; Zhao, G. Supporting sustainable maintenance of substations under cybersecurity risk for power CPS. Sustainability 2019, 11, 982. [CrossRef]

29. Gómez, T.; Rivier, J. Distribution and power quality regulation under electricity competition. A comparative study. In Proceedings of the IEEE 9th International Conference on Harmonics and Quality of Power, Orlando, FL, USA, 1-4 October 2000; pp. 462-468. [CrossRef]

30. Joskow, P.L. Incentive regulation in theory and practice: Electricity distribution and transmission networks. In Economic Regulation and Its Reform: What Have We Learned? Rose, N.L., Ed.; University of Chicago Press: Chicago, IL, USA, 2014; pp. 291-344.

31. CEER. Report on Investment Conditions in European Countries; Council of European Energy Regulators: Brussels, Belgium, 2016.

32. BOE. Real Decreto 1048/2013, de 27 de Diciembre, por el que se Establece la Metodología Para el Cálculo de la Retribución de la Actividad de Distribución de Energía Eléctrica, Boletín Oficial del Estado, 312 de 30 Diciembre de 2013; Ministerio de la Presidencia, Relaciones con las Cortes y Memoria Democrática: Madrid, Spain, 2013. 